\title{
Effect of soil water availability on photosynthesis in Ziziphus jujuba var. spinosus in a sand habitat formed from seashells: Comparison of four models
}

\author{
J.B. XIA*, G.C. ZHANG ${ }^{* *}$, R.R. WANG ${ }^{* *}$, and S.Y. ZHANG ${ }^{* *,+}$ \\ Shandong Provincial Key Laboratory of Eco-Environmental Science for Yellow River Delta, Binzhou University, \\ Binzhou, 256603, China* \\ Shandong Province Key Laboratory of Soil Erosion and Ecological Restoration, Key Laboratory of Agricultural Ecology \\ and Environment, Forestry College, Shandong Agricultural University, Taian, 271018, China**
}

\begin{abstract}
The photosynthetic and chlorophyll fluorescence parameters were studied in Ziziphus jujuba var. spinosus under different soil water gradients obtained by irrigation and natural water consumption. We used the rectangular hyperbola model, the nonrectangular hyperbola model, the exponential model, and the modified rectangular hyperbola model to fit our data and evaluate them quantitatively. Based on the relationship among the parameters, the effects of the availability of soil water on photosynthesis were elucidated. The results showed that: (1) The relationship between water content and photosynthetic parameters were fitted best by the modified rectangular hyperbola model, followed by the nonrectangular hyperbola model, the exponential model, and the rectangular hyperbola model. The modified rectangular hyperbola model fitted best the maximum net photosynthetic rate $\left(P_{\mathrm{Nmax}}\right)$ and the light-saturation point (LSP), while the nonrectangular hyperbola model fitted best the dark respiration rate $\left(R_{\mathrm{D}}\right)$, the apparent quantum yield (AQY), and the light-compensation point (LCP). (2) The main reason for the net photosynthetic rate $\left(P_{\mathrm{N}}\right)$ decline was that it reached a stomatal limit when the soil relative water content (RWC) was greater than $25 \%$ and it reached a nonstomatal limit when the RWC was lesser than $25 \%$. Under these conditions, the photosynthetic apparatus of $Z$. jujuba was irreversibly damaged. (3) $P_{\max }, R_{\mathrm{D}}$, AQY, and LSP increased first and then decreased, while LCP increased contrary to the RWC. The $P_{\mathrm{N}}$ light-response parameters reached optimum when the RWC was 56-73\%. (4) The quantum yield of PSII photochemistry reached a maximum when RWC was $80 \%$. Nonphotochemical quenching decreased rapidly, and the minimum fluorescence in the dark-adapted state increased rapidly when RWC was lesser than $25 \%$. Under these conditions, PSII was irreversibly damaged. (5) The RWC range of $11-25 \%$ resulted in low productivity and low water use efficiency (WUE). The RWC range of $25-56 \%$ resulted in moderate productivity and moderate WUE, and the RWC range of 56-80\% resulted in high productivity and high WUE. The RWC range of 80-95\% resulted in moderate productivity and low WUE. In summary, photosynthesis of $Z$. jujuba was physiologically adaptable in response to water stress in sand formed from seashells. The photosynthetic and physiological activity was maintained relatively high when the RWC was between 56 and $80 \%$; $Z$. jujuba seedlings grew well under these conditions.
\end{abstract}

Additional key words: chlorophyll fluorescence, light-response model; photosynthetic productivity; relative water content.

Received 5 October 2013, accepted 11 March 2014.

${ }^{+}$Corresponding author; fax:+865388249164, e-mail: zhsy@sdau.edu.cn

Abbreviations: AQY - apparent quantum yield; $C_{\mathrm{i}}$ - intercellular $\mathrm{CO}_{2}$ concentration; $E$ - transpiration rate; EM - exponential model $\mathrm{FC}$ - field capacity; $\mathrm{F}_{\mathrm{m}}$ - maximum fluorescence of the dark-adapted state; $\mathrm{F}_{\mathrm{m}}{ }^{\prime}$ - maximuml fluorescence yield; $\mathrm{F}_{0}-$ minimum fluorescence yield of the dark-adapted state; $F_{s}$ - steady-state fluorescence; $F_{v} / F_{m}$ - maximum quantum yield of PSII photochemistry; $g_{\mathrm{s}}$ - stomatal conductance; GWC - gravitational water content; LCP - light-compensation point; $L_{\mathrm{s}}$ - stomatal limiting value; LSP light-saturation point; MRHM - modified rectangular hyperbola model; NPQ - nonphotochemical quenching; NRHM - nonrectangular hyperbola model $P_{\mathrm{Nmax}}$ - maximum net photosynthetic rate; $P_{\mathrm{N}}$ - net photosynthetic rate; $R^{2}$ - determination coefficient; $R_{\mathrm{D}}-$ dark respiration rate; RE - relative error; RHM - rectangular hyperbola model; RWC - relative water content; WUE - water-use efficiency; $\Phi_{\text {PSII }}$ - effective quantum yield of PSII photochemistry.

Acknowledgements: This study was supported by the National Natural Science Foundation of China (No. 31100468 and No. 31100196), the promotive research fund for excellent young and middle-aged scientists of Shandong Province (BS2013NY010), and the Major State Basic Research Development Program (No. 2012CB416904/zgc).

J.B. Xia and G.C. Zhang contributed equally to this work.

(C) The Author(s). 2014 This article is published with open access at link.springer.com 


\section{Introduction}

Photosynthetic efficiency is a critical factor in plant productivity and crop yield (Peng 2000). Soil water availability strongly limits plant photosynthesis, growth, and yield. This is especially true now due to water shortages and droughts across the world (Chaves et al. 2003, Islam et al. 2008, Varela et al. 2010). The key objective of water-saving agroforestry is using limited water resources productively in the field (Deng et al. 2006, Kang et al. 2007). Much research focused on the effects of soil water content on photosynthetic and water-use efficiency (Galmés et al. 2007, Zhang et al. 2007a, Xia et al. 2011b, Wang et al. 2012). However, many of these studies were limited to fewer than eight water gradients and ignored variations in water availability. These limitations resulted in unclear quantitative relationships between photosynthetic parameters and soil water content.

Measuring $P_{\mathrm{N}}$ and fitting these data to a model is important to understand photosynthesis. It allows to determine parameters, such as AQY, $R_{\mathrm{D}}$, LCP, LSP, and $P_{\text {max }}$. These parameters can reflect photosynthetic efficiency (Robert et al. 1984) and have been used to generate lightresponse models (Webb et al. 1974, Ye 2010, Lang et al. 2013). Thus, the commonly used models include the rectangular hyperbola model (Lewis et al. 1999), the nonrectangular hyperbola model (Thornley 1998), the exponential model (Prado and deMoraes 1997), and the modified rectangular hyperbola model (Ye 2007), all of which have certain advantages and disadvantages. These models are usually evaluated qualitatively (Duan and Zhang 2009, Lang et al. 2013), which restricts their accuracy in determining how well the data fit the models.

The shell ridge island of Yellow River Delta in China

\section{Materials and methods}

Plants: The experimental site was located in the research greenhouse of the Shandong Key Laboratory of EcoEnvironmental Science for the Yellow River Delta in the Shandong Province. In the greenhouse, the light intensity was approximately $85 \%$ of that of the natural light in the area. The temperature was $18-30^{\circ} \mathrm{C}$, the $\mathrm{CO}_{2}$ concentration $345-365 \mu \mathrm{mol} \mathrm{mol}{ }^{-1}$ and the relative humidity 41-65\%. The experimental substrate was shell sand/soil (Table 1) collected from the wild jujube community in October of 2011; the sand grains with a diameter greater than $2 \mathrm{~mm}$ were removed with a sieve. The average soil is a special ecological system formed by seashells and their debris, which accumulate near the high tide line. The soil salinity was the main factor to the seaside of shell ridge island land side, where the vegetation mainly included halophytes. The shell sand/soil does not retain water well due to its high altitude, low groundwater level, large soil porosity, and high content of coarse sand. Together with a high evaporation to precipitation ratio and serious seasonal water shortages in this region, these properties inhibit a growth of vegetation. Therefore the vegetation includes mainly xerophytic shrubs and herbs, and the ecological environment is very fragile. Z. jujuba var. spinosus, which conserves soil nutrients and water, benefits from the shell ridge island and is a preferred species for restoring vegetation and ecological reconstruction efforts. Much of the previous research on this species has focused on its chemical, medicinal, and economic value (Cheng et al. 2000, Peng et al. 2000, Outlaw et al. 2002). The applicability of the light-response models and the quantitative relationships between the main photosynthetic parameters and the soil water content remain unclear. Therefore, studies on the physiological characteristics of drought resistance in $Z$. jujuba var. spinosus are limited in their application to other species and site conditions.

In this study, four models describing the effects of soil water content on photosynthesis in Z. jujuba var. spinosus leaves were evaluated by using a gradient of water levels and measuring the main photosynthetic parameters and chlorophyll fluorescence. The light-response parameter, $P_{\mathrm{N}}$, was fitted to these models to provide a theoretical standard for site selection for Z. jujuba var. spinosus.

density was $1.3 \mathrm{~g} \mathrm{~cm}^{-3}$; the average field capacity (FC) was $24 \%$. The experimental samples were selected from 3-year-old Z. jujuba var. spinosus plants in the shell ridge island of Yellow River Delta, China. Nine plants were planted in plastic pots $(80 \mathrm{~cm}$ long $\times 40 \mathrm{~cm}$ wide $\times 80 \mathrm{~cm}$ high) in the greenhouse; this volume was sufficient for unrestricted root growth. The mean root diameter on the ground was $0.8 \pm 0.1 \mathrm{~cm}$ and the mean plant height was $0.7 \pm 0.08 \mathrm{~m} ; 5$ best-growing plants were selected for the experiments after 120 days.

Table 1. The physical characteristics of the shell sand soil.

\begin{tabular}{|c|c|c|c|c|c|c|c|c|c|}
\hline \multirow[t]{2}{*}{ Sample } & \multicolumn{4}{|c|}{ Soil particle-size fractions [\%] } & \multirow{2}{*}{$\begin{array}{l}\text { Bulk density } \\
{\left[\mathrm{g} \mathrm{cm}^{-3}\right]}\end{array}$} & \multirow{2}{*}{$\begin{array}{l}\text { Total porosity } \\
{[\%]}\end{array}$} & \multirow{2}{*}{$\begin{array}{l}\text { Capillary } \\
\text { porosity [\%] }\end{array}$} & \multirow{2}{*}{$\begin{array}{l}\text { Noncapillary } \\
\text { porosity [\%] }\end{array}$} & \multirow[t]{2}{*}{ Void ratio } \\
\hline & Gravel & Coarse sand & Fine sand & Silt-clay & & & & & \\
\hline Shell sand & 17.33 & 61.31 & 19.97 & 1.39 & 1.25 & $47.42 \%$ & $45.14 \%$ & $2.28 \%$ & 0.91 \\
\hline
\end{tabular}


The design of the water gradient: A water gradient was generated in the sand by providing water first and then allowing the plants to transpire. The soil in the pots of 5 sample plants was sufficiently watered for 2 days before the examination period (July 12-13, 2012). Then, the soil water was gradually reduced by plant transpiration from July 14, 2012, until the end of the experiment (August 11, 2012). Meanwhile, the soil surface was covered with a plastic film to prevent soil water evaporation. The soil gravitational water content (GWC) of the 5 samples was measured by the oven-drying method on every sunny day (1-2 d intervals). Three samples from each pot were measured. The average relative soil water content (RWC) was calculated on each sunny day as RWC $=\mathrm{GWC} / \mathrm{FC}$. Eighteen water gradients were obtained and varied from 11.2 to $94.6 \%$ during the experiment.

Experimental methods: The main gas-exchange parameters, including $P_{\mathrm{N}}$, transpiration rate $(E)$, stomatal conductance $\left(g_{\mathrm{s}}\right)$, and intercellular $\mathrm{CO}_{2}$ concentration $\left(C_{\mathrm{i}}\right)$ were measured in 5 mature leaves at the center of each plant in response to light. The same leaf was measured 3 times. This was performed using a portable photosynthesis system (LI-COR 6400, LI-COR Inc., Lincoln, NE, USA) between 9:00-11:30 $\mathrm{h}$ on the same days when the GWC was measured. A relative humidity was maintained at $45 \%$, air temperature of leaf chamber was maintained at about $33^{\circ} \mathrm{C}$, and the flow rate of air in the measuring chamber was $200 \mu \mathrm{mol} \mathrm{m} \mathrm{m}^{-2}$. WUE and the stomatal limiting value $\left(L_{\mathrm{s}}\right)$ in response to light were calculated according to the formulas WUE $=P_{\mathrm{N}} / E$ (Frank et al. 1987) and $L_{\mathrm{s}}=1-C_{\mathrm{i}} / C_{\mathrm{a}}$ (Farquhar and Sharkey 1982), where $C_{\mathrm{a}}$ is the atmospheric $\mathrm{CO}_{2}$ concentration. The PPFD was held constant at 1,600; 1,$400 ; 1,200 ; 1,000 ; 800,600,400,200$, $150,100,80,40$ or $20 \mu \mathrm{mol} \mathrm{m}^{-2} \mathrm{~s}^{-1}$, with an interval of $120 \mathrm{~s}$ by $L I$-COR LED (LI-COR Inc., Lincoln, NE, USA) irradiation source.

\section{Results}

Fitting the light responses to the models: The lightresponse curves of $Z$. jujuba var. spinosus leaves under different water conditions were fitted to 4 models, such as the RHM, the NRHM, the EM, and the MRHM. All 4 models fitted the light-response curves well, as shown by the determination coefficients $\left(R^{2} \geq 97.5 \%\right)$, although there were some differences (Table 2). The average $R^{2}$ value from the MRHM (99.983\%) was greater than that for the EM $(99.867 \%)$. These values were followed by those of the NRHM (99.861\%) and the RHM (99.250\%) (Table 2). To evaluate the accuracy of the 4 models, the relative error (RE) was calculated according to the formula: $\mathrm{RE}=$ $\left|\left(\mathrm{y}_{\mathrm{t}}-\hat{\mathrm{y}}_{\mathrm{t}}\right) / \mathrm{y}_{\mathrm{t}}\right| \times 100 \%$, where $\hat{\mathrm{y}}_{\mathrm{t}}$ is the measured value and $\mathrm{y}_{\mathrm{t}}$ is the fitted value; neither of these values can be 0 .

The greater the RE, the greater the deviation of the measured value from the fitted value. The smaller the RE, the better is the fit of the model to the data. When the RWC
The main chlorophyll fluorescence parameters were measured in 3 mature leaves at the center of each plant using a portable fluorometer (FMS-2, Hansatech, Kings Lynn, UK) at the same time as the gas-exchange parameters. Different leaves were used for these 2 types of measurements. The minimum fluorescence of the darkadapted state $\left(\mathrm{F}_{0}\right)$ and the maximum fluorescence of the dark-adapted state $\left(\mathrm{F}_{\mathrm{m}}\right)$ were determined after the leaf samples were dark-adapted for $1 \mathrm{~h}$. Then the steady-state fluorescence $\left(\mathrm{F}_{\mathrm{s}}\right)$ and the maximum fluorescence yield $\left(\mathrm{F}_{\mathrm{m}}{ }^{\prime}\right)$ were determined in response to $1 \mathrm{~h}$ of natural light. The maximum quantum yield of PSII photochemistry $\left(\mathrm{F}_{\mathrm{v}} / \mathrm{F}_{\mathrm{m}}\right)$, the effective quantum yield of PSII photochemistry $\left(\Phi_{\mathrm{PSII}}\right)$, and the nonphotochemical quenching (NPQ) were calculated according to the formula $F_{v} / F_{m}=$ $\left(\mathrm{F}_{\mathrm{m}}-\mathrm{F}_{0}\right) / \mathrm{F}_{\mathrm{m}}$, where $\Phi_{\mathrm{PSII}}=\left(\mathrm{F}_{\mathrm{m}}{ }^{\prime}-\mathrm{F}_{\mathrm{s}}\right) / \mathrm{F}_{\mathrm{m}}{ }^{\prime}$ and $\mathrm{NPQ}=$ $\left(\mathrm{F}_{\mathrm{m}}-\mathrm{F}_{\mathrm{m}}{ }^{\prime}\right) / \mathrm{F}_{\mathrm{m}}{ }^{\prime}$ (Genty et al. 1989, Gilmore and Yamamoto 1991).

Data processing: The $P_{\mathrm{N}}$ curves were drawn, and $P_{\max }, R_{\mathrm{D}}$, AQY, LCP, and LSP were estimated from the curves (Ye 2010). These data were fitted to the rectangular hyperbola model (RHM), the nonrectangular hyperbola model (NRHM), the exponential model (EM), and the modified rectangular hyperbola model (MRHM) (Lang et al. 2013) using SPSS 18.0 (Chicago, IL, USA). Two dimensional contour line maps of gas-exchange parameters showing the RWC and the PPFD were generated using Origin 8.0 (Easthampton, MA, USA). The quantitative relationships between the soil water content and the light-response parameters or the main chlorophyll fluorescence parameters were identified by polynomial regression analysis and integral solutions using Origin 8.0 systematic cluster analysis. The analysis of the soil water content was carried out using SPSS 18.0. Significant differences between the treatments at a 0.05 significance level were determined using the Student's $t$-test function in SPSS 18.0.

was $31.94 \%$, the PPFD was $40 \mu \mathrm{mol} \mathrm{m} \mathrm{m}^{-2} \mathrm{~s}^{-1}$, the $P_{\mathrm{N}}$ was $0 \mu \mathrm{mol} \mathrm{m} \mathrm{m}^{-2} \mathrm{~s}^{-1}$, and the fitted values of the RHM, the NRHM, the EM, and the MRHM were $-0.17,-0.05,-0.09$, and $-0.08 \mu \mathrm{mol} \mathrm{m}^{-2} \mathrm{~s}^{-1}$, respectively. Therefore, the RHM provided the worst fit to the data. Under other soil water and light intensity conditions, the mean RE of the $P_{\mathrm{N}}$ lightresponse curve was $3.86 \%$ for the MRHM, $4.13 \%$ for the NRHM, $5.47 \%$ for the EM, and $11.99 \%$ for the RHM (Table 2). These data indicated that the MRHM fitted best the $P_{\mathrm{N}}$ curves. The NRHM provided the second-best fit; it was followed by the EM and then by the RHM. The mean RE of the $P_{\mathrm{N}}$ light-response parameters was $18.93 \%$ for the RHM, $24.68 \%$ for the NRHM, $37.91 \%$ for the EM, and $64.55 \%$ for the RHM (Table 2). This order was consistent with that for the $P_{\mathrm{N}}$ light-response curves, while the mean $\mathrm{RE}$ of the $P_{\mathrm{N}}$ light-response parameters was greater than that for the $P_{\mathrm{N}}$ light-response curves for every model. This 
Table 2. Fitting four models to the net photosynthetic rate $\left(P_{\mathrm{N}}\right)$-light response curves and parameters in Ziziphus jujuba var. spinosus leaves. Each value of $P_{\mathrm{N}}$ is the mean of 15 replicates. $R^{2}$ - determination coefficient; $R_{\mathrm{D}}-$ respiration rate; AQY - apparent quantum yield; LCP - light compensation point; $P_{\max }$ - maximum net photosynthetic rate; LSP - light saturation point. RHM - rectangular hyperbola model; NRHM - nonrectangular hyperbola model; EM - exponential model; MRHM - modified rectangular hyperbola model.

\begin{tabular}{lllllllll}
\hline Light-response model & Average $R^{2}[\%]$ & $\begin{array}{l}\text { Average relative error [\%] } \\
\text { Light-response } \\
\text { curve }\end{array}$ & $\begin{array}{l}\text { Light-response } \\
\text { parameter }\end{array}$ & $R_{\mathrm{D}}$ & AQY & LCP & $P_{\max }$ & LSP \\
\hline RHM & 11.990 & 64.547 & 79.619 & 115.142 & 2.386 & 48.658 & 76.932 \\
NRHM & 99.250 & 4.130 & 24.679 & 14.861 & 18.056 & 1.553 & 22.680 & 66.247 \\
EM & 99.861 & 5.473 & 37.908 & 35.191 & 46.014 & 7.441 & 18.598 & 82.294 \\
MRHM & 99.867 & 3.859 & 18.933 & 36.523 & 51.921 & 1.631 & 0.461 & 4.128 \\
\hline
\end{tabular}
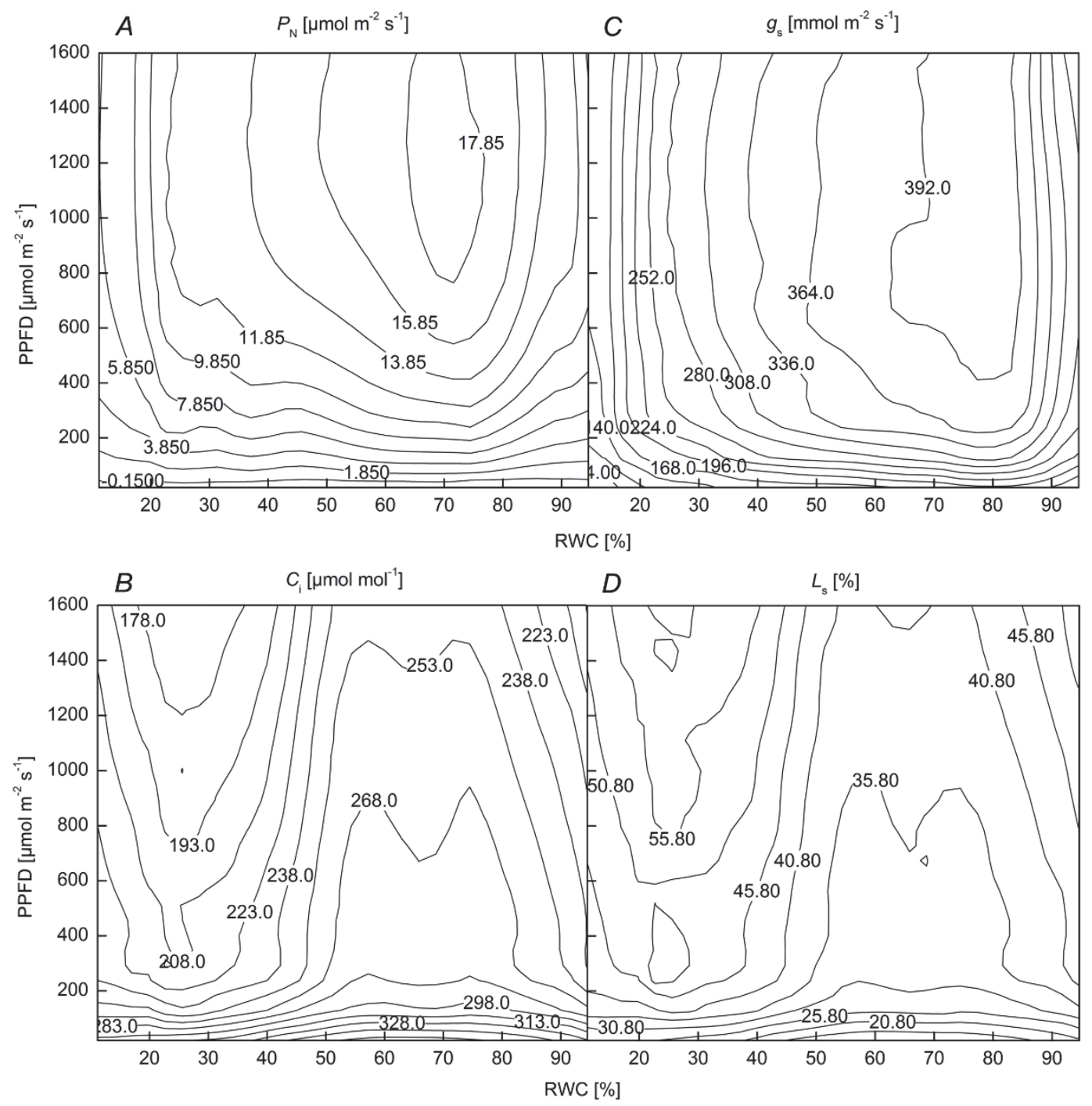

Fig. 1. The response to light and soil water of the net photosynthetic rate $\left(P_{\mathrm{N}}\right)$, the stomatal conductance $\left(g_{\mathrm{s}}\right)$, the intercellular $\mathrm{CO}_{2}$ concentration $\left(C_{\mathrm{i}}\right)$, and the stomatal limitation values $\left(\mathrm{L}_{\mathrm{s}}\right)$ for Ziziphus jujuba var. spinosus. Each value of $P_{\mathrm{N}}$ is the mean of 15 replicates fitted to the modified rectangular hyperbola model, and the other parameter values are the means of 15 replicates. RWC - relative water content. 


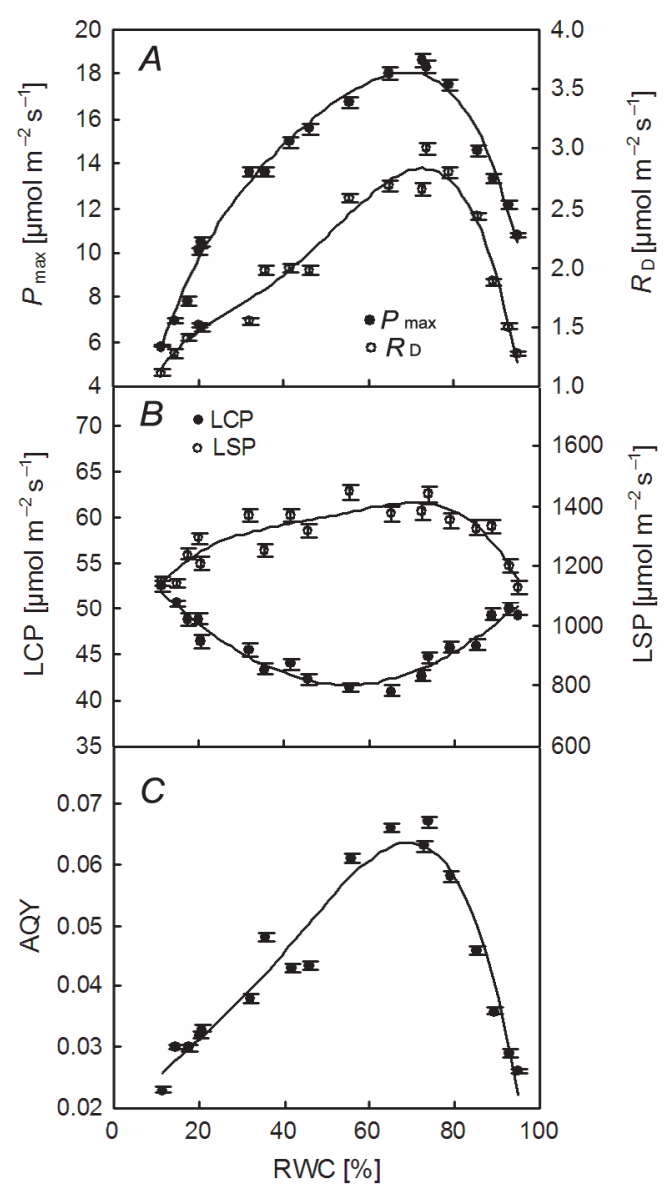

Fig. 2.The values of the maximum net photosynthetic rate $\left(P_{\max }\right)$ and the light saturation point (LSP) as determined by the modified rectangular hyperbola model. The respiration rate $\left(R_{\mathrm{D}}\right)$, light compensation point (LCP), and apparent quantum yield (AQY) were fitted to the nonrectangular hyperbola model for various water content levels. Each value is the mean $\pm \mathrm{SE}$ $(n=15)$. RWC - relative water content.

result showed that the models fitted the $P_{\mathrm{N}}$ light-response curves better than the $P_{\mathrm{N}}$ light-response parameters. The NRHM fitted the $R_{\mathrm{D}}$ the best because the average RE of the $R_{\mathrm{D}}$ from this model was the lesser than those from the other models. Therefore, the NRHM also provided the best fit for the AQY and the LCP, and the MRHM provided the best fit for the $P_{\max }$ and the LSP (Table 2).

Light response of gas-exchange parameters: The MRHM best fitted the $P_{\mathrm{N}}$ light-response curves and therefore the estimated $P_{\mathrm{N}}$ value from this model was used instead of the measured $P_{\mathrm{N}}$ value. Photosynthesis was mainly inhibited by light intensity when PPFD $\leq 400 \mu \mathrm{mol}$ $\mathrm{m}^{-2} \mathrm{~s}^{-1}$. Photosynthesis was not substantially affected by soil water, and the main gas-exchange parameters were consistent at high light intensities (Fig. 1). $P_{\mathrm{N}}$ increased first quickly and then slowly as PPFD and RWC increased (Fig. $1 A) . P_{\mathrm{N}}$ reached its maximum when the RWC was $72 \%$ (Fig. $1 A$ ), indicating that $P_{\mathrm{N}}$ was affected by drought and waterlogging stress. The response pattern of $g_{\mathrm{s}}$ to the soil water content and light intensity was similar to that of $P_{\mathrm{N}} . g_{\mathrm{s}}$ reached a maximum when the RWC was $74 \%$ (Fig. 1C). This result might be related to the ability of $Z$. jujuba var. spinosus to control carbon assimilation by stomata opening and closing. $C_{\mathrm{i}}$ decreased with the increase in PPFD (Fig. 1B), indicating a trend of "decreaseincrease - stationary - decrease" with the increase of the RWC. The response pattern of $L_{\mathrm{s}}$ to soil water content and light intensity was essentially the opposite to that of $C_{\mathrm{i}}$ (Fig. 1D).

$P_{\mathrm{N}}, g_{\mathrm{s}}$, and $L_{\mathrm{s}}$ decreased and $C_{\mathrm{i}}$ increased when the RWC was 11-25\% (Fig. 1), indicating that photosynthesis was mainly restrained by the nonstomatal limitation under severe drought stress. $P_{\mathrm{N}}, g_{\mathrm{s}}$, and $L_{\mathrm{s}}$ increased and $C_{\mathrm{i}}$ decreased when the RWC was $25-55 \%$ or $80-95 \%$ (Fig. 1), suggesting that photosynthesis was mainly restrained by the stomatal limitation under light, drought or waterlogging stress. $P_{\mathrm{N}}$ and $g_{\mathrm{s}}$ were high and $C_{\mathrm{i}}$ and $L_{\mathrm{s}}$ were constant when the RWC was $55-80 \%$, showing that the photosynthetic activity was higher under suitable water conditions.

$\boldsymbol{P}_{\mathrm{N}}$ light-response parameters: $R_{\mathrm{D}}, \mathrm{AQY}$, and LCP were studied fitting the data to the NRHM. $P_{\max }$ and LSP were studied fitting the data to the MRHM. The quantitative relationships between $P_{\max }, R_{\mathrm{D}}, \mathrm{AQY}, \mathrm{LCP}$, or LSP and the soil water content were determined using a quartic equation. The fit precision was relatively high; $R^{2}$ was

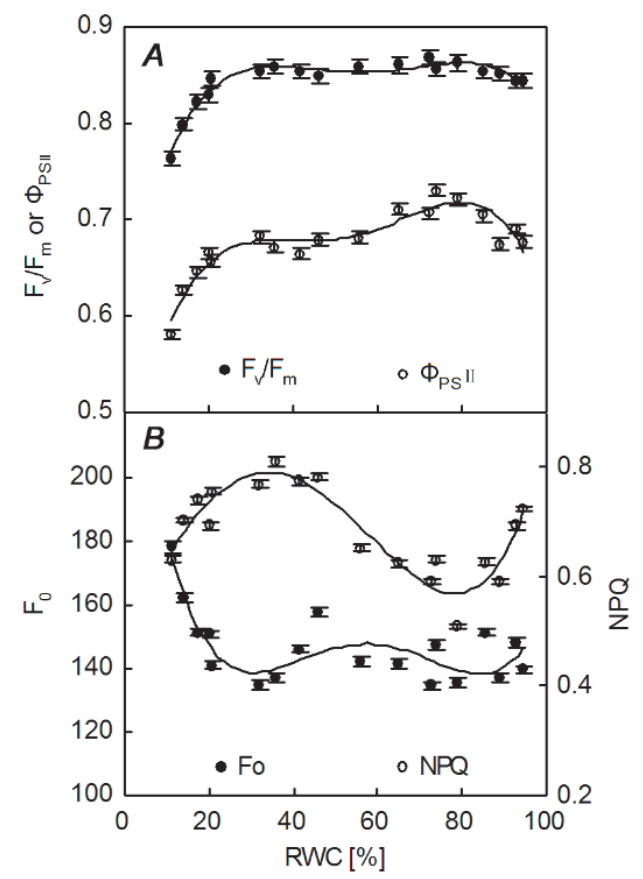

Fig. 3. The maximum quantum yield of PSII photochemistry $\left(\mathrm{F}_{\mathrm{v}} / \mathrm{F}_{\mathrm{m}}\right)$, the effective quantum yield of PSII photochemistry (ФPSII), the minimum fluorescence of the dark-adapted state $\left(\mathrm{F}_{0}\right)$, and the nonphotochemical quenching (NPQ) for Ziziphus jujuba var. spinosus under different water content levels. Each value represents the mean $\pm \mathrm{SE}(n=15)$. RWC - relative water content. 
Table 3. The soil water productivity for Ziziphus jujuba var. spinosus in response to different relative water content (RWC). Different letters indicate significant differences $(P<0.05) . P_{\mathrm{N}}-$ net photosynthetic rate; WUE - water-use efficiency.

\begin{tabular}{lclll}
\hline RWC [\%] & \multicolumn{2}{c}{ Cluster mean \pm SE } & Soil water productivity and WUE & RWC predictive threshold [\%] \\
& $P_{\mathrm{N}}\left[\mu \mathrm{mol} \mathrm{m} \mathrm{m}^{-1}\right]$ & WUE $\left[\mu \mathrm{mol} \mathrm{mmol}^{-1}\right]$ & & \\
\hline $11,15,17,20,21$ & $8.32 \pm 0.866^{\mathrm{c}}$ & $3.08 \pm 0.134^{\mathrm{c}}$ & Low productivity, low WUE & $11-25$ \\
$32,36,42,46,56$ & $14.22 \pm 0.536^{\mathrm{b}}$ & $3.80 \pm 0.030^{\mathrm{b}}$ & Middle productivity, middle WUE & $25-56$ \\
$65,73,74,79$ & $18.40 \pm 0.268^{\mathrm{a}}$ & $4.13 \pm 0.048^{\mathrm{a}}$ & High productivity, high WUE & $56-80$ \\
$85,89,93,95$ & $14.22 \pm 0.536^{\mathrm{b}}$ & $3.08 \pm 0.134^{\mathrm{c}}$ & Middle productivity, low WUE & $80-95$ \\
\hline
\end{tabular}

Table 4. The results of researchers about grading criterion of soil water productivity and availability. RWC - relative water content.

\begin{tabular}{|c|c|c|c|}
\hline $\begin{array}{l}\text { Grading of soil water productivity } \\
\text { and availability }\end{array}$ & $\begin{array}{l}\text { Range of RWC [\%] } \\
\text { Robinia pseudoacacia } \\
\text { (Zhang et al. } 2012 \text { ) }\end{array}$ & $\begin{array}{l}\text { Platycladus orientalis } \\
\text { (Zhang et al. 2012) }\end{array}$ & $\begin{array}{l}\text { Prunus sibirica } \\
\text { (Xia et al. 2011a) }\end{array}$ \\
\hline Non-productivity and non-efficiency water & $<21.5$ & $<19.0$ & - \\
\hline Low productivity and middle efficiency water & - & - & $>81.8 \%$ and $<33.5 \%$ \\
\hline Low productivity and low efficiency water & $21.5 \sim 47.5$ and $>90.5$ & $19.0 \sim 40.5$ and $>90.5$ & - \\
\hline Middle productivity and high efficiency water & $47.5 \sim 64.0$ & $40.5 \sim 52.0$ & - \\
\hline Middle productivity and middle efficiency water & - & - & $33.5 \% \sim 46.9 \%$ \\
\hline High productivity and middle efficiency water & $64.0 \sim 81.0$ & $52.0 \sim 76.0$ & - \\
\hline High productivity and high efficiency water & - & - & $46.9 \% \sim 74.5 \%$ \\
\hline Middle productivity and low efficiency water & $81.0 \sim 90.5$ & $76.0 \sim 90.5$ & $74.5 \% \sim 81.8 \%$ \\
\hline
\end{tabular}

0.8299-0.9848. $P_{\max }, R_{\mathrm{D}}, \mathrm{AQY}$, and LSP first increased and then decreased (Fig. 2); LCP first decreased and then increased with the increasing RWC (Fig. 2B). The response thresholds of different parameters varied (Fig. 2). $P_{\max }$ reached a maximum of $18.1 \mu \mathrm{mol} \mathrm{m} \mathrm{m}^{-2} \mathrm{~s}^{-1}$ when the RWC was $69 \%$ and an average of $14.6 \mu \mathrm{mol} \mathrm{m}^{-2} \mathrm{~s}^{-1}$ when the RWC was 39 and $88 \%$ (Fig. $2 A$ ). This result was based on extremum and integral solutions of the quartic equation and indicated that $P_{\max }$ was maintained at a higher lever when the RWC was $38-88 \%$ (Fig. $2 A$ ). $P_{\max }$ decreased with water stress. $R_{\mathrm{D}}, \mathrm{AQY}$, and LSP reached maxima of $2.8,0.064$, and $1,410 \mu \mathrm{mol} \mathrm{m} \mathrm{m}^{-2} \mathrm{~s}^{-1}$, when the RWC was 73 , 69 , and $71 \%$, respectively (Fig. 2). All of these parameters decreased with drought stress $(\mathrm{RWC}<40 \%)$ and waterlogging stress (RWC $>90 \%$ ). LCP decreased to a minimum of $42 \mu \mathrm{mol} \mathrm{m} \mathrm{m}^{-1}$, when the RWC was $56 \%$, and it increased, when the RWC was less than $30 \%$ or greater than $80 \%$ (Fig. $2 B$ ). All of the $P_{\mathrm{N}}$ light-response parameters reached their optimum levels when the RWC was 56-73\% (Fig. 2). Adequate water conditions improved light-use efficiency and photosynthetic activity, while water stress reduced these parameters.

Chlorophyll fluorescence parameters: The quantitative relationships between $\mathrm{F}_{\mathrm{v}} / \mathrm{F}_{\mathrm{m}}, \Phi_{\mathrm{PSII}}, \mathrm{F}_{0}$, or NPQ and the soil water content were also fitted to a quartic equation (Fig. 3). $R^{2}$ was $0.689-0.952$, and $\mathrm{F}_{\mathrm{v}} / \mathrm{F}_{\mathrm{m}}$ was larger than $\Phi_{\text {PSII }}$ (Fig. $3 A$ ). All of these parameters reached their maxima when the RWC was $80 \%$. The PSII photochemistry efficiency was also the highest at this RWC (Fig. 3A).
$\mathrm{F}_{\mathrm{v}} / \mathrm{F}_{\mathrm{m}}$ and AQY were used as key indices of photoinhibition (Demmig-Adams and Adams 1992). All chlorophyll fluorescence parameters decreased upon drought stress when the RWC was lesser than 30\% (Fig. 3), indicating substantial photoinhibition. The NPQ increased upon drought stress (RWC of 30-80\%) and waterlogging stress (RWC of $80-95 \%$ ) (Fig. 3B), indicating that PSII can dissipate heat to protect the photosynthetic apparatus from damage when the RWC is 30-95\% (Gilmore and Yamamoto 1991). The NPQ decreased and the $F_{0}$ increased when the RWC was lesser than $25 \%$ (Fig. $3 B$ ), indicating that PSII was irreversibly damaged (Demmig and Björkman 1987, Krause 1988). This water threshold was consistent with that of the photosynthetic nonstomatal limit.

Grading criterion of soil water productivity: Systematic cluster analysis was used to analyze the effect of water content on the $P_{\mathrm{N}}$ and the WUE under saturated light intensity. The number of clusters was set to 3 , and $P_{\mathrm{N}}$ and WUE were designated the "productivity" and "efficiency" of photosynthesis, respectively (Zhang et al. 2012). The RWC was divided into bins of $11-21 \%, 32-56 \%, 85-95 \%$, and $65-79 \%$ (Table 3); the corresponding clusters had low, middle, and high productivity. The RWC was divided into $11-21 \%$ and $85-95 \%, 32-56 \%$ and $65-79 \%$ bins based on the WUE; the WUE in the corresponding clusters was designated as low, middle, or high (Table 3 ). The photosynthetic and fluorescence parameters reached optimum levels, when the RWC was $56-80 \%$, and the main limit on photosynthesis changed from the stomatal to the 
nonstomatal limitation, when the RWC was reduced to $25 \%$ (Table 3 ). Therefore, 25,56 , and $80 \%$ were used as key critical points in dividing the soil water levels into bins. The range of the RWC from 11.2 to $25 \%$ resulted in low productivity and low WUE (Table 3). From 25 to 56\%,

\section{Discussion}

Fitting the data to the $P_{\mathrm{N}}$ light-response models is important in studying photosynthesis. Recently, a number of models have been quantitatively evaluated by calculating the mean absolute error, the mean square error, or the root mean square error (Chen et al. 2011, Li et al. 2011). However, these evaluation indices have limitations in evaluating the fit of different parameters. In this study, the RE was used to address this difficulty. The result showed that the MRHM fitted best the $P_{\mathrm{N}}$ light-response curves and parameters and the NRHM provided the next best fit. It was followed by the EM and the RHM. The MRHM fitted the $P_{\mathrm{N}}$ and other parameters at high light intensities (Ye 2007), and the NRHM fitted under other conditions because it introduced another parameter to the RHM (Lu et al. 2001). The order of the models from best to worst fit was consistent with the results of studies on winter wheat (Li et al. 2011) and Populus szechuanica Schneid (Wang et al. 2011). The MRHM fitted the $P_{\max }$ and the LSP well, and the NRHM fitted the $R_{\mathrm{D}}$, the AQY, and the LCP. These data indicated that the MRHM is suitable for light-response parameters at high light intensities and the NRHM is suitable for response parameters at low light intensities.

The stomatal limitation theory (Farquhar and Sharkey 1982, Zhang et al. 2010) states that the effect of soil water stress on photosynthesis is divided into the stomatal and the nonstomatal limit. The former comes from stomata closure and reduced gas exchange, which reversibly affect photosynthesis. The latter comes from damage to the photosynthetic apparatus, which has an irreversible effect on photosynthesis. Plants regulate photosynthesis by the stomatal limit to respond to drought stress, and the nonstomatal limit affects photosynthetic potential and drought resistance (Wang et al. 2012). The turning point from the stomatal to the nonstomatal limit determines the soil water maximum deficit that the plant can tolerate. We found that the main reason for the $P_{\mathrm{N}}$ decline in $Z$. jujuba var. spinosus was the change from the stomatal to the nonstomatal limitation when the RWC was reduced to $25 \%$. The turning point for Malus pumila cv. Goldspur (Zhang et al. 2010) and Hippophae rhamnoides Linn. (Pei et al. 2013) occurred when the RWCs were $48 \%$ and $39 \%$, respectively. Therefore, the turning points of different species varied, while the turning point of $Z$. jujuba var. spinosus occurred under severe drought stress. This result indicated that the photosynthetic apparatus of $Z$. jujuba var. spinosus adapted well to drought stress.

Intricate relationship between fluorescence kinetics and photosynthesis underlies photosynthetic biophysical the range of the RWC resulted in moderate productivity and moderate WUE. From 56 to $80 \%$, the range of the RWC resulted in high productivity and high WUE. From 80 to $94.6 \%$, the range of the RWC resulted in moderate productivity and low WUE.

processes. Chlorophyll fluorescence techniques have been used extensively to assess quickly and harmlessly plant responses to environmental stress (Sayed 2003). The responses of photosynthesis and fluorescence parameters to the soil water content indicated that Z. jujuba var. spinosus grown in sand formed from seashells had strong photosynthetic capacity and it showed also great physiological adaptability. The range of RWC from 11.2 to $25 \%$ resulted in low productivity and low WUE; it also reduced seedling growth. This finding might indicate that the photosynthetic apparatus, mainly the PSII reaction centers, was irreversibly damaged. The range of RWC from 25 to $56 \%$ resulted in moderate productivity and moderate WUE; the range of RWC from 80 to $94.6 \%$ resulted in moderate productivity and low WUE. Between these 2 ranges, photosynthetic productivity was kept at a moderate level, because it was restrained by the stomatal limitations in a reversible manner. The WUE was restrained to different degrees depending on drought or waterlogging stress. The range of the RWC from 56 to $80 \%$ resulted in high productivity and high WUE, and the photosynthesis and fluorescence parameters reached all optimum levels, resulting in the robust plant growth.

The parameters $P_{\mathrm{N}}$ and WUE indicate "productivity" and "efficiency" and are useful for describing moisture availability. Soil water productivity measurements were only recently standardized. Zhang et al. (2012) and Chen et al. (2008) determined first the quantitative relationships between the photosynthetic parameters $\left(P_{\mathrm{N}}, \mathrm{WUE}, E\right.$, and $L_{\mathrm{s}}$ ) and the soil water content. They also determined the critical points (extremum, average, compensation point, and turning point) of those parameters by a nonlinear regression analysis and integral solution, and then divided the soil water content into different productivity levels based on those critical points. Extremum means the critical point, e.g., the water saturation point of $P_{\mathrm{N}}$, water saturation point of WUE; average included the mean value point of $P_{\mathrm{N}}$ and WUE; the compensation point means the water compensation point of $P_{\mathrm{N}}$; the turning point means the turning point from stomatal limitation to nonstomatal limitation of $P_{\mathrm{N}}$. Xia et al. (2011b) and Zhang et al. (2007b) classified the soil water content by cluster analysis based on the main photosynthetic parameters $\left(P_{\mathrm{N}}\right.$, WUE, and $\left.E\right)$. This study performed a cluster analysis on the RWC using the $P_{\mathrm{N}}$ and the WUE separately, which resulted in a more detailed cluster analysis than using all of the photosynthetic parameters. Our analysis combined the threshold effects of photosynthesis and the fluorescence parameters with soil water content and used the mathematical 
intersection calculation principle to establish water grading criteria. However, it needs to be determined, which grading method applies best to experimental results.

In areas suffering from drought, the soil water threshold of high productivity and high WUE or moderate productivity and high WUE was designated as a suitable water condition for plant growth (Table 4). However, high productivity and moderate WUE were also considered suitable, e.g., in the RWC range of 48 to 64\% in Robinia pseudoacacia and of 41 to $52 \%$ in Platycladus orientalis (Zhang et al. 2012). The suitable RWC for other plants was: $60-71 \%$ for the goldspur apple tree (Zhang et al. 2010), 47-75\% for Prunus sibirica (Xia et al. 2011a), 44-85\% for Aralia elata (Chen et al. 2008), and 44-72\% for Euonymus fortunei var. radicans (Zhang et al. 2007). The water ecological amplitudes of arbor trees (Robinia pseudoacacia and Platycladus orientalis) and a fruit tree (goldspur apple) were relatively narrow. Robinia pseudoacacia and Platycladus orientalis are adapted to a mild drought habitat, and the goldspur apple tree is adapted to a moderate water content habitat. The water ecological amplitudes of shrub trees (Z. jujuba var. spinosus, Prunus sibirica, and Aralia elata) and liana (Euonymus fortunei var. radicans) were relatively high, and these species are adapted to different water habitats. Therefore, the suitable water conditions for various plants depend on the plant species and the habitat.

Open Access This article is distributed under the terms of the Creative Commons Attribution License which permits any use, distribution, and reproduction in any medium, provided the original author(s) and the source are credited.

\section{References}

Chaves, M.M., Maroco, J.P., Pereira, J.S.: Understanding plant responses to drought-from genes to the whole plant. - Funct. Plant Biol. 30: 239-264, 2003.

Chen, J., Zhang, G.C., Zhang, S.Y., Wang, M.J.:[Response processes of Aralia elata photosynthesis and transpiration to light and soil moisture.] - Chin. J. Appl. Ecol. 19: 1185-1190, 2008. [In Chinese]

Chen, Z.Y., Peng, Z.S., Yang, J. et al.: A mathematical model for describing light-response curves in Nicotiana tabacum L.. Photosynthetica 49: 467-471, 2011.

Cheng, G., Bai, Y.J., Zhao, Y.Y. et al.: Flavonoids from Ziziphus jujuba Mill var. spinosa. - Tetrahedron 56: 8915-8920, 2000.

Demmig-Adams, B., Adams, W.W.: Photoprotection and other responses of plants to high light stress. - Annu. Rev. Plant Phys. 43: 599-626, 1992.

Demmig, B., Björkman, O.: Comparison of the effect of excessive light on chlorophyll fluorescence $(77 \mathrm{~K})$ and photon yield of $\mathrm{O}_{2}$ evolution of leaves of higher plants. - Planta 171: 171-184, 1987.

Deng, X.P., Shan, L., Zhang, H.P., Turner, N.C.: Improving agricultural water use efficiency in arid and semiarid areas of China. - Agric. Water Manage. 80: 23-40, 2006.

Duan, A.G., Zhang, J.G.: [Selection of models of photosynthesis in response to irradiance and definition of attribute of weak light.] - Forest Res. 22: 765-771, 2009. [In Chinese]

Farquhar, G.D., Sharkey, T.D.: Stomatal conductance and photosynthesis. - Annu. Rev. Plant Physiol. 33: 317-345, 1982.

Frank, A.B., Barker, R.E., Berdahl, J.D.: Water-use efficiency of grasses grown under controlled and field conditions. - Agron. J. 79: 541-544, 1987.

Galmés, J., Abadía, A., Medrano, H., Flexas, J.: Photosynthesis and photoprotection responses to water stress in the wild-extinct plant Lysimachia minoricensis. - Environ. Exp. Bot. 60: 308317, 2007.

Genty, B., Briantais, J.M., Baker, N.R.: The relationship between the quantum yield of photosynthetic electron transport and quenching of chlorophyll fluorescence. - Biochim. Biophys. Acta 990: 87-92, 1989.

Gilmore, A.M., Yamamoto, H.Y.: Zeaxanthin formation and energy-dependent fluorescence quenching in pea chloroplasts under artificially mediated linear and cyclic electron transport.
- Plant Physiol. 96: 635-643, 1991.

Islam, M.R., Hamid, A., Karim, M.A. et al.: Gas exchanges and yield responses of mungbean (Vigna radiata L. Wilczek) genotypes differing in flooding tolerance. - Acta Physiol. Plantarum 30: 697-707, 2008.

Kang, S.Z., Du, T.S., Sun, J.S., Ding, R.S.: Theory and technology of improving irrigation water use efficiency based on crop growing water demand information. - J. Hydr. Eng. 38: 1-7, 2007.

Krause, G.H.: Photoinhibition of photosynthesis: an evaluation of damaging and protective mechanisms. - Physiol. Plantarum 74: 566-574, 1988.

Lang, Y., Wang, M., Zhang, G.C., Zhao, Q.K.: Experimental and simulated light responses of photosynthesis in leaves of three tree species under different soil water conditions. Photosynthetica 51: 370-378, 2013.

Lewis, J.D., Olszyk, D., Tingey, D.T.: Seasonal patterns of photosynthetic light response in Douglas-fir seedlings subjected to elevated atmospheric $\mathrm{CO}_{2}$ and temperature. - Tree Physiol. 19: 243-252, 1999.

Li, Y.X., Yang, Z.Q., Zhang, F.C.:[ Applicability of different photosynthesis models for winter wheat in the Lower Yangtze River.] - Chin. J. Agrometeorol. 32: 588-592, 2011. [In Chinese]

Lu, P.L., Yu, Q., Luo, Y., Liu, J.D.: [Fitting Light response curves of photosynthesis of winter wheat.] - Agr. Meteorol. 22: 12-14, 2001. [In Chinese]

Outlaw, W.H., Zhang, S.Q., Riddle, K.A. et al.: The jujube (Ziziphus jujuba Mill.), a multipurpose plant. - Econ. Bot. 56: 198-200, 2002.

Pei, B., Zhang, G.C., Zhang, S.Y et al.: [Effects of soil drought stress on photosynthetic characteristics and antioxidant enzyme activities in Hippophae rhamnoides Linn. seedings.] - Acta Ecol. Sinica 33: 1386-1396, 2013. [In Chinese]

Peng, S.: Single-leaf and canopy photosynthesis of rice. - In: Sheehy, J.E., Mitchell, P.L., Hardy, B. (ed.): Redesigning Rice Photosynthesis to Increase Yield. Pp. 213-228. Elsevier Science Publ., Amsterdam 2000.

Peng, W.H., Hsieh, M.T., Lee, Y.S. et al.: Anxiolytic effect of seed of Ziziphus jujuba in mouse models of anxiety. - J. Ethnopharmacol. 72: 435-441, 2000. 
Prado, C.H.B.A., deMoraes, J.A.P.V.: Photosynthetic capacity and specific leaf mass in twenty woody species of Cerrado vegetation under field condition. - Photosynthetica 33: 103$112,1997$.

Sayed, O.H.: Chlorophyll fluorescence as a tool in cereal crop research. - Photosynthetica 41: 321-330, 2003.

Sharp R.E., Matthews M.A., Boyer, J.S.: Kok effect and the quantum yield of photosynthesis. - Plant Physiol. 75: 95-101, 1984.

Thornley, J.H.M.: Dynamic model of leaf photosynthesis with acclimation to light and nitrogen. - Ann. Bot. 81: 421-430, 1998.

Varela, S.A., Gyenge, J.E., Fernández, M.E., Schlichter, T.: Seedling drought stress susceptibility in two deciduous Nothofagus species of NW Patagonia. - Trees 24: 443-453, 2010.

Wang, S.J., Huang, D.Z., Yan, H.X. et al..: [Applicability of four empirical models on photosynthesis light response of Populus szechuanica Schneid.] - J. Beihua Univ. 12: 208-212, 2011. [In Chinese]

Wang, Z.X., Chen, L., Ai, J. et al.: Photosynthesis and activity of photosystem II in response to drought stress in Amur Grape (Vitis amurensis Rupr.). - Photosynthetica 50: 189-196, 2012.

Webb, W.L., Newton, M., Starr, D.: Carbon dioxide exchange of Alnus rubra: A mathematical model. - Oecologia 17: 281-291, 1974.

Xia, J.B., Zhang, G.C., Sun, J.K., Liu, X.: [Threshold effects of photosynthetic and physiological parameters in Prunus sibirica to soil moisture and light intensity.] - Chin. J. Plant Ecol. 35:
322-329, 2011a. [In Chinese]

Xia, J.B., Zhang, S.Y., Zhang, G.C. et al.: Critical responses of photosynthetic efficiency in Campsis radicans (L.) Seem to soil water and light intensities. - Afr. J. Biotechnol. 10: 1774817754, $2011 \mathrm{~b}$.

Ye, Z.P.: A new model for relationship between irradiance and the rate of photosynthesis in Oryza sativa. - Photosynthetica 45: 637-640, 2007.

Ye, Z.P.: [A review on modeling of responses of photosynthesis to light and $\mathrm{CO}_{2}$.] - Chin. J. Plant Ecol. 34: 727-740, 2010. [In Chinese]

Zhang, G.C., Xia, J.B., Shao, H.B., Zhang, S.Y.: Grading woodland soil water productivity and soil bioavailability in the semi-arid Loess Plateau of China. - Clean-Soil Air Water 40: 148-153, 2012.

Zhang, S.Y., Xia, J.B., Zhou, Z.F., Zhang, G.C.: Photosynthesis responses to various soil moisture in leaves of Wisteria sinensis. - J. Forestry Res. 18: 217-220, 2007a.

Zhang, S.Y., Zhang, G.C., Gu, S.Y. et al.: Critical responses of photosynthetic efficiency of goldspur apple tree to soil water variation in semiarid loess hilly area. - Photosynthetica 48: 589$595,2010$.

Zhang, S.Y., Zhou, Z.F., Xia et al.: [The responses of Euonymus fortunei var. radicans Sieb. leaf photosynthesis to light in different soil moisture.] - Acta Bot. Boreali-Occidentalia Sinica 27: 2514-2521, 2007b. [In Chinese] 